\title{
Effects of drought on expression patterns of genes encoding the antioxidant enzymes associated with chloroplasts in wheat
}

\author{
S.F. DANYALI ${ }^{1}$, M. MOGHADDAM VAHED ${ }^{1 *}$, S.S. ALAVIKIA ${ }^{1}$, H. SAMIZADEH LAHIJI ${ }^{2}$, \\ and M. NOROUZI ${ }^{1}$ \\ Department of Plant Breeding and Biotechnology, Faculty of Agriculture, University of Tabriz, Tabriz, \\ 5166614671, Iran $^{l}$ \\ Department of Plant Biotechnology, Faculty of Agricultural Sciences, University of Guilan, Rasht, \\ 4199613776, Iran $^{2}$
}

\begin{abstract}
Reactive oxygen species lead to cellular damage and in plants exposed to drought stress, an increasing expressions of genes encoding antioxidant enzymes play important protective roles. The aim of this study was to evaluate response of drought tolerant ('Arg' and 'Roshan') and drought sensitive ('Arta' and 'Navid') wheat cultivars to oxidative stress caused by drought. Relative water content (RWC), water loss rate (WLR), free proline content, malondialdehyde (MDA) accumulation, and peroxidase (POX) activity were measured after 2, 4, 6, and $8 \mathrm{~h}$ of dehydration. The tolerant cultivars had a higher RWC and lower MDA, proline content, POX activity and WLR as compared to the sensitive cultivars. Real-time quantitative PCR was used to measure the expressions of genes encoding antioxidant enzymes in chloroplastic thylakoids and stroma. The expressions of chloroplastic $\mathrm{Cu} / \mathrm{Zn}$ superoxide dismutase, thylakoid-bound ascorbate peroxidase, monodehydroascorbate reductase, dehydroascorbate reductase, and chloroplastic glutathione reductase genes were up-regulated in the tolerant cultivars. A direct relationship between physiological traits and increased gene expressions was observed for both sensitive and tolerant cultivars. Overall, increasing gene expressions protect the plants from oxidative damage caused by dehydration stress and improves tolerance to this stress.
\end{abstract}

Additional key words: ascorbate-glutathione cycle, malondialdehyde, proline, relative water content, ROS scavenging, water-water cycle.

\section{Introduction}

Water deficit is considered as the most common environmental stress and a major constraint to plant productivity (Hernández et al. 2012). Many factors affect the plant responses to drought stress such as plant genotype, growth stage, severity and duration of stress (Chaves et al. 2003), gene expression (Denby and Gehring 2005), respiration activity (Carbo-Ribas et al. 2005), photosynthetic activity (Flexas et al. 2004), and other environmental factors (McDonald and Davies 1996, Rizhsky et al. 2002). Drought stress leads to oxidative stress by increasing the accumulation of reactive oxygen species (ROS). The ROS attack lipids, proteins, saccharides, nucleic acids and, eventually, cause cell death
(Smirnoff 1993). Plants exposed to stresses use various approaches including physiological, biochemical, and molecular mechanisms to counteract their harmful effects. One of the most important defense mechanisms against drought is activation of the antioxidant system, which scavenges ROS and keeps an adequate redox balance.

The most important antioxidant enzymes are involved in water-water and ascorbate-glutathione (AsA-GSH) cycles (Asada 1999, Hernández et al. 2009). Because of the electron flow from water in photosystem II to water in photosystem I that occurs in this process across thylakoid membranes, water-water cycle takes part in ROS detoxification and scavenging excess photon energy (Peroni et al. 2007). The most important issue in this cycle is rapid sweeping $\mathrm{O}_{2}{ }^{-}$and $\mathrm{H}_{2} \mathrm{O}_{2}$ by $\mathrm{Cu} / \mathrm{Zn}$ superoxide

Submitted 11 June 2018, last revision 17 February 2019, accepted 19 February 2019.

Abbreviations: APX - ascorbate peroxidase; AsA - ascorbic acid; CAT - catalase; DHAsA - dehydroascorbate; DHAR - dehydroascorbate reductase; GR - glutathione reductase; GSH - glutathione; GSSG - oxidized glutathione; MDA - malondialdehyde; MDAR monodehydroascorbate reductase; MDAsA - monodehydroascorbate; POX - peroxidase; RWC - relative water content; sAPX - stromatal APX; SOD - superoxide dismutase; tAPX - thylakoid-bound ascorbate peroxidase; WLR - water loss rate.

Acknowledgments: We are grateful to the Department of Biotechnology and Plant Breeding, Faculty of Agriculture, University of Guilan, Iran, with regard to all cooperations needed to implement this research.

* Corresponding author; e-mail: mmoghaddam@tabrizu.ac.ir 
dismutase (SOD, as the major isoform of SOD, EC 1.15.1.1, in almost all plant species) or Fe SOD (in several plant species) and thylakoid-bound ascorbate peroxidase (tAPX) at the site of production before they affect the target molecules (Asada 1999, Peroni et al. 2007). The SOD can protect chloroplasts from the threat of increasing $\mathrm{O}_{2}{ }^{-}$by converting it to $\mathrm{H}_{2} \mathrm{O}_{2}$ and $\mathrm{O}_{2}$. Then, tAPX enzyme converts $\mathrm{H}_{2} \mathrm{O}_{2}$ into water using two AsA molecules (Peroni et al. 2007). In addition to water-water cycle, AsA-GSH cycle located in the stroma of chloroplast prohibits the accumulation of ROS (Asada 1992). The AsA-GSH cycle provides another position for reducing $\mathrm{H}_{2} \mathrm{O}_{2}$ to water. The AsA-GSH cycle is active in most subcellular organelles such as mitochondria and cytoplasm, in spite of the fact that it is present in chloroplast. The enzymes APX (EC 1.11.1.11), monodehydroascorbate reductase (MDAR, EC 1.6.5.4), dehydroascorbate reductase (DHAR, EC 1.8.5.1), and glutathione reductase (GR, EC 1.8.1.7) participate in AsA-GSH cycle and depending on their activities in certain organelles have various isoforms; for example, stromal APX (sAPX), chlMDHAR, chlDHAR, and chlGR in chloroplasts. During this cycle, APX reduces $\mathrm{H}_{2} \mathrm{O}_{2}$ through AsA, and the product of this reaction is MDAsA that is reduced with MDAR to AsA (Asada 1999). The MDAsA may also be converted to dehydroascorbate (DHAsA) through non-enzymatic disproportionation and then DHAR reduces DHAsA to AsA, which is connected with GSH oxidation (Sečenji et al. 2010) to oxidized glutathione (GSSG). Since GSH is one of the most important antioxidants in plant cells, GSSG is rapidly reduced to GSH by GR using NAD(P)H as a reducing agent (Sečenji et al. 2010).

The tolerance of plants to abiotic stresses, such as drought, is related to the activation of antioxidant enzymes, which has been proven by several studies (Kang and Saltveit 2002, Simova-Stoilova et al. 2008, Xiaoqin et al. 2009, Yang et al. 2011, Chakraborty and Pradhan 2012). Increasing the expression of antioxidant enzyme encoding genes in order to protect against oxidative damage caused by drought stress can be considered as one of the molecular changes to increase the tolerance of plants to drought stress (Hernández et al. 2012). In this regard, the best way to understand the activity of antioxidant enzymes under stress conditions is to examine the expression of their genes. Several studies have been conducted to investigate the activity of antioxidant enzymes under stress conditions in wheat, but few studies have investigated expression of their genes; especially, the whole cycle in a particular organelle has been rarely studied. Increasing the expression of APX, SOD, and catalase (CAT) genes and their activities in barley genotypes, was observed under severe drought stress, especially in the drought resistant genotype (Harb et al. 2015). Peroxidase (POX), cytosolic APX (cytAPX), and CAT genes show higher expressions in a tolerant cultivar of canola under severe drought stress as compared to a susceptible cultivar (Hosseini et al. 2015). Sečenji et al. (2010) stated that the low expression of genes encoding APX, DHAR, and GR isoforms in a susceptible cultivars of wheat indicated that they do not have sufficient protection against oxidative stress caused by water deficiency. High expressions of the enzymes encoding genes of AsA-GSH cycle play an important role in protecting against cold stress in wheat (Baek and Skinner 2003) and eggplant (Chen et al. 2011). It has been proven that high expressions of the genes encoding antioxidant enzymes in plants improves the protection against ROS caused by abiotic stresses (Baek and Skinner 2003).

The aim of this investigation was to study the expressions of genes encoding the antioxidant enzymes in the thylakoid (water-water cycle) and stromal (AsA-GSH cycle) sections in wheat chloroplasts with the exception of the SAPX gene and to evaluate the physiological and biochemical responses of four cultivars to dehydration. Contrary to previous works, the present study is focused on the expression of these genes in one organelle.

\section{Materials and methods}

Plants, growth conditions, and dehydration: Seeds of uniform size from 'Arta' and 'Navid' (susceptible) and 'Arg' and 'Roshan' (tolerant) wheat cultivars that were obtained from the Seed and Plant Improvement Institute, Karaj, Iran, were washed with distilled water and sterilized using $0.1 \%(\mathrm{~m} / \mathrm{v}) \mathrm{HgCl}_{2}$ for $5 \mathrm{~min}$ and then washed with deionized water. Next, 10 seeds of each cultivar were sown in pots filled with sterilized soil. Seedlings were grown in a greenhouse (Guilan University, Iran) under a 16-h photoperiod, an irradiance of $300 \mu \mathrm{mol} \mathrm{m} \mathrm{m}^{-2}$, day/night temperatures of $20-24 / 16^{\circ} \mathrm{C}$, and a $65-75 \%$ relative humidity. They were regularly irrigated with tap water.

The dehydration treatment was used as the best drought stress simulator (Malatrasi et al. 2002, Liu and Baird 2003, Rampino et al. 2006). Two-week-old seedlings of the similar leaf size were transferred on dry filter paper and left at room temperature for 0 (control), 2, 4, 6, and $8 \mathrm{~h}$. After completing each stage of stress, samples were frozen in the liquid nitrogen and stored at $-80^{\circ} \mathrm{C}$ for gene expression and biochemical assessments.

Total RNA extraction and quantitative real-time PCR: Total RNA was extracted from leaves by an RNA isolation kit (DENAzist, Mashhad, Iran) according to recommended protocol with a slight modification. After purifying the genomic DNA from RNA, cDNA was synthesized by a synthesis kit of the first strand cDNA (RevertAid, Thermo Fischer Scientific, San Jose, USA) according to the manufacturer's recommendation using oligo (dt) 15 as a primer. Quantitative real-time PCR was performed on a BioRad-C1000 (Hercules, USA) real-time detection system using GreenHot Master Mix (BIORON, Germany). Each reaction containing $6.25 \mathrm{~mm}^{3}$ of $2 \times$ Green Hot Master Mix (including active Syber Green dye and Super Hot Taq DNA polymerase), $1 \mathrm{~mm}^{3}$ of cDNA template, $4.25 \mathrm{~mm}^{3}$ of sterile deionized water, and $0.5 \mathrm{~mm}^{3}$ of each primer in a total volume of $12.5 \mathrm{~mm}^{3}$ was carried out three times under the following protocol: $95{ }^{\circ} \mathrm{C}$ for $3 \mathrm{~min}, 45$ cycles at $95{ }^{\circ} \mathrm{C}$ for $30 \mathrm{~s}$, an appropriate primer-specific annealing temperature for $30 \mathrm{~s}$, and at $72{ }^{\circ} \mathrm{C}$ for $30 \mathrm{~s}$. In order to verify 
the uniqueness of real-time PCR products, the following two criteria were used: 1) a single peak melting curves measured at the end of each PCR reaction, and 2) a single band on agarose gel electrophoresis. The expression level of each target gene was normalized by comparing with $18 s r R N A$ as a reference gene and the internal control. The relative quantification of the gene expression was carried out using the $2^{-\triangle \Delta C T}$ methodology (Livak and Schmittgen 2001).

Primer design: Sequences of the genes under study were identified by searching in the NCBI databases (www.ncbi.nlm.nih.gov). All genes, except GR, were designed based on the wheat gene sequences related to chloroplast organelle using the Primer 3 program (http://primer3.ut.ee). The chloroplastic GR sequence related to barley (Hordeum vulgare L.) was used to design the GR primer. The sequences of MDAR and DHAR genes were aligned from the chloroplastic MDAR and DHAR sequences of different cereal species (such as rice, barley, and maize) by the tcoffee program (http://tcoffee.crg.cat/ apps/tcoffee/do:mcoffee), and the sections of sequences having a very high overlap were chosen for the primer designing. Primer sequences, amplified fragment length, and accession numbers of genes are listed in Table 1 Suppl.

Assay of physiological and biochemical characteristics: In order to measure relative water content (RWC), fresh mass (FM) of the leaves was immediately recorded after imposing $0,2,4,6$, and $8 \mathrm{~h}$ of drought stress. The leaves were then immersed in distilled water for $4 \mathrm{~h}$ under ambient temperature. After $4 \mathrm{~h}$, samples were slightly dried with a tissue paper and their water-saturated mass (WSM) was determined. Then the samples were dried at $80{ }^{\circ} \mathrm{C}$ for $24 \mathrm{~h}$ and their dry mass (DM) was measured. RWC was determined according to Barrs and Weatherley (1962) using the following formula: $\mathrm{RWC}[\%]=[(\mathrm{FM}-\mathrm{DM}) /(\mathrm{WSM}-\mathrm{DM})] \times 100$.

After imposing $0,2,4,6$, and 8 h of dehydration stress, the first fully expanded leaf was cut and its FM was immediately recorded. The leaf was then dried at $80^{\circ} \mathrm{C}$ for $24 \mathrm{~h}$ and total DM was determined. Water loss rate (WLR) was computed based on Suprunova et al. (2004) with a slight modification: $\mathrm{WLR}\left[\mathrm{g} \mathrm{h}^{-1} \mathrm{~g}^{-1}(\mathrm{DM})\right]=\left[\left(\mathrm{FM}_{\mathrm{Tx}}-\mathrm{FM}_{\mathrm{Tx}+2}\right)\right] /[\mathrm{DM} \times(\mathrm{Tx}+2-$ - Tx)], where Tx $=0,2,4$, and $8 \mathrm{~h}$.

The enzyme extract for the analysis of POX activity and lipid peroxidation was prepared as follows: $0.5 \mathrm{~g}$ of leaf powder was homogenized in $1 \mathrm{~cm}^{3}$ of $10 \mathrm{mM}$ extraction buffer [consisting of $0.68 \%(\mathrm{~m} / \mathrm{v}) \mathrm{KH}_{2} \mathrm{PO}_{4}$ and $0.87 \%(\mathrm{~m} / \mathrm{v}) \mathrm{K}_{2} \mathrm{HPO}_{4} \cdot 12 \mathrm{H}_{2} \mathrm{O}, \mathrm{pH}$ 7.2]. The solution was then centrifuged at $12000 \mathrm{~g}$ and $4{ }^{\circ} \mathrm{C}$ for $15 \mathrm{~min}$. The supernatant was used to measure POX activity and lipid peroxidation. In order to determine lipid peroxidation, $1 \mathrm{~g}$ of polyvinylpyrrolidone and $0.0186 \mathrm{~g} \mathrm{Na}_{2}$-EDTA were added to the extraction buffer.

Activity of POX (EC 1.11.1.7) was determined according to Chance and Maehly (1955): $485 \mathrm{~mm}^{3}$ of $40 \mathrm{mM} \mathrm{H}_{2} \mathrm{O}_{2}$ and $485 \mathrm{~mm}^{3}$ of $20 \mathrm{mM}$ guaiacol were mixed together at a low temperature and then $30 \mathrm{~mm}^{3}$ of the enzyme extract was added. The changes in absorbance at
$470 \mathrm{~nm}$ for $1 \mathrm{~min}$ were observed by a spectrophotometer (T80+UV-VIS, PG Instruments, Coventry, UK). The enzyme concentration was determined by the LambertBeer law and a guiacol peroxidase coefficient of absorbance was $26.6 \mathrm{mM}^{-1} \mathrm{~cm}^{-1}$. One unit of POD activity was defined as an absorbance change of 0.01 .

Lipid peroxidation was assayed as malondialdehyde (MDA) content produced through a thiobarbituric acid reaction according to Heath and Packer (1968): $600 \mathrm{~mm}^{3}$ of the enzyme extract was mixed with $600 \mathrm{~mm}^{3}$ of $20 \%$ $(\mathrm{m} / \mathrm{v})$ trichloroacetic acid. The mixture was kept at a temperature of $95^{\circ} \mathrm{C}$ for $30 \mathrm{~min}$ in a hot water bath and then immediately cooled on ice and centrifuged at $10000 \mathrm{~g}$ and $4{ }^{\circ} \mathrm{C}$ for $10 \mathrm{~min}$. The supernatant was used for determining absorbance at $532 \mathrm{~nm}$, from which the absorbance of other non-specific pigments at $600 \mathrm{~nm}$ was deducted. Content of MDA was determined using a coefficient of absorbance of $155 \mathrm{mM}^{-1} \mathrm{~cm}^{-1}$.

Proline content was measured as described by Bates et al. (1973): $0.1 \mathrm{~g}$ of powdered leaf sample was homogenized in $1.5 \mathrm{~cm}^{3}$ of $3 \%(\mathrm{~m} / \mathrm{v})$ sulphosalicylic acid and after centrifuging the reaction mixture at $9000 \mathrm{~g}$ for $12 \mathrm{~min}, 1 \mathrm{~cm}^{3}$ of glacial acetic acid and $1 \mathrm{~cm}^{3}$ of $2.5 \%(\mathrm{~m} / \mathrm{v})$ ninhydrin (1.25 $\mathrm{g}$ of ninhydrin dissolved in a mixture of $30 \mathrm{~cm}^{3}$ of glacial acetic acid and $20 \mathrm{~cm}^{3}$ of $6 \mathrm{M}$ phosphoric acid) were added to supernatant. The mixture was heated at $100{ }^{\circ} \mathrm{C}$ for $60 \mathrm{~min}$, and then the reaction was stopped by incubating in an ice bath. Then, $2 \mathrm{~cm}^{3}$ of toluene was added to the mixture and mixed vigorously for $15-20 \mathrm{~s}$. The absorbance of the red upper phase was measured at $520 \mathrm{~nm}$. A standard curve was used for calculating proline content.

Data analysis: Statistical analyses of physiological and biochemical attributes, including the Tukey test for comparing means, were performed by the $S A S v .9$ software (SAS Institute, Chicago USA) using three replications. Furthermore, principal component analysis was carried out by the Minitab statistical software (v. 14), using all 10 attributes under study, for comparing wheat responses to dehydration stress between stress-tolerant and stresssusceptible genotypes. In order to remove the scale effect, correlation matrix, instead of covariance matrix, was utilized to extract the principal components.

\section{Results}

The highest expression of the $c h l C u / Z n$ SOD gene was observed in 'Roshan' (Fig. 1A). The expression was 7and 8-times higher than in the control after 6 and $8 \mathrm{~h}$ of dehydration, respectively. After $2 \mathrm{~h}$ of dehydration, gene expression was maximum in 'Arg', and then it severely decreased at $4 \mathrm{~h}$ of stress. Afterwards, at $6 \mathrm{~h}$, it was about 7-times higher, but after $8 \mathrm{~h}$, only a slight increase in expression was observed in relation to the control. Regarding the susceptible 'Arta' and 'Navid', chlCu/Zn $S O D$ gene expression decreased with the onset of stress, and this reduction was higher in 'Arta' as compared to 'Navid' at all time points. 


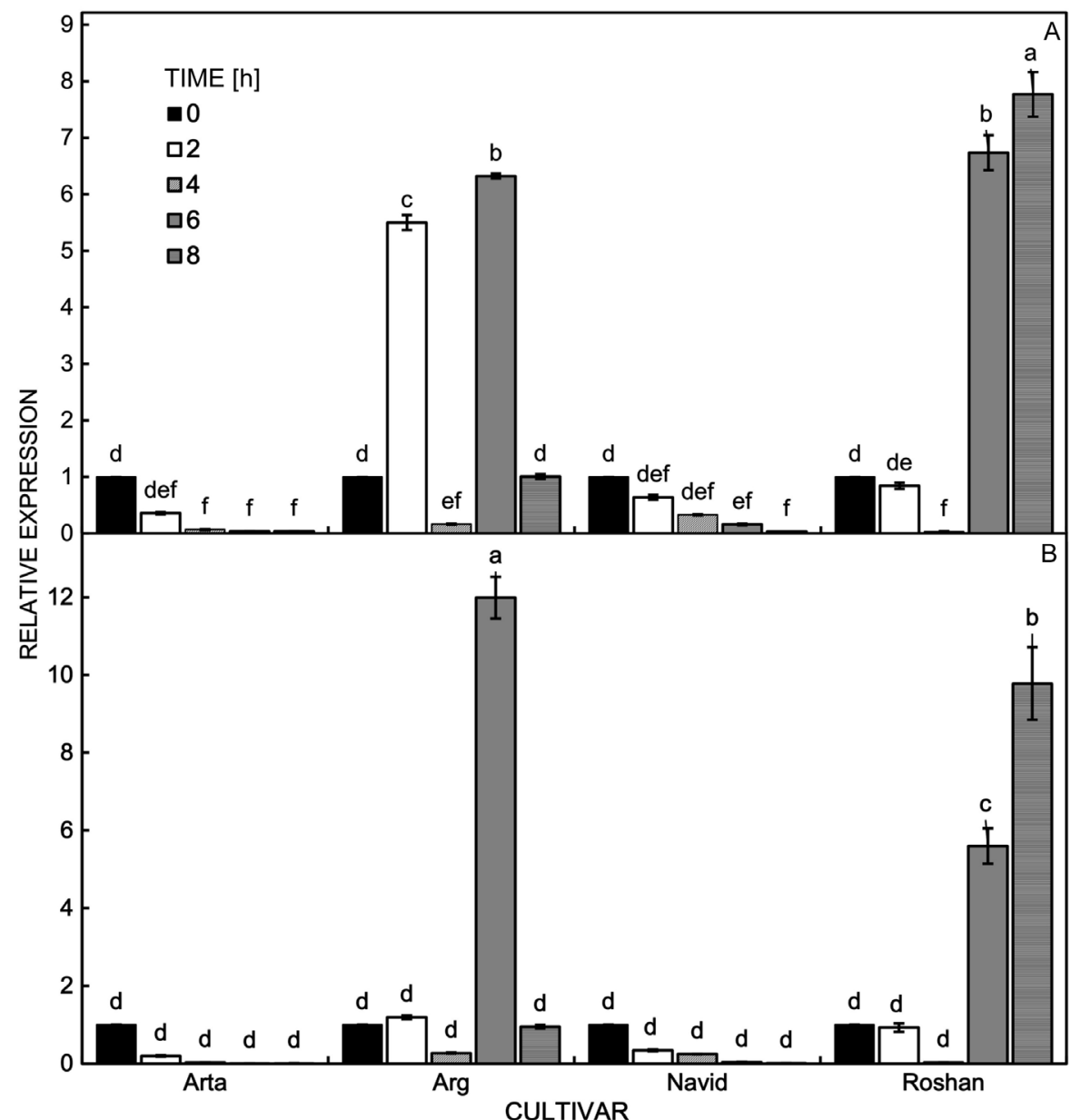

Fig. 1. Expression patterns of genes encoding enzymes of thylakoid water-water cycle in wheat cultivars Arta, Arg, Navid, and Roshan. Means \pm SEs, $n=3$. Means with different letters are significantly different at $P \leq 0.05$ based on the Tukey test. Relative expressions of $\operatorname{chlCu} / \mathrm{Zn} \operatorname{SOD}(A)$ and $t A P X(B)$.

Expression of the $t A P X$ gene in the non-tolerant 'Arta' and 'Navid' decreased during water stress. The expression of the $t A P X$ gene in 'Arg' increased slightly at $2 \mathrm{~h}$ of stress and, then increased 12-fold at $6 \mathrm{~h}$ as compared to the control. Expression in tolerant 'Roshan' at 6 and $8 \mathrm{~h}$ of stress was 6- and 10-times higher than in the control, respectively (Fig. $1 B$ ).

Increasing the expression of the $M D A R$ gene relative to the control for susceptible 'Arta' was observed only at $2 \mathrm{~h}$ of the stress and the expression of this gene decreased with increasing the stress period (Fig. $2 A$ ). In tolerant 'Arg', the expression increased only at $6 \mathrm{~h}$ of stress and decreased in other time points. For sensitive 'Navid', the gene expression was higher than in the control during the whole stress except after $4 \mathrm{~h}$ when the reduction of gene expression was observed. In tolerant 'Roshan', expression increased about 4-times at 2 and $6 \mathrm{~h}$ of dehydration, and after $8 \mathrm{~h}$, it increased 8 -times as compared to the control.

The expression of the DHAR gene was low in 'Arta' and 'Navid' and decreased as the stress period increased (Fig. 2B). In 'Arg', the highest expression of DHAR was observed at $6 \mathrm{~h}$ of stress, when it was higher than in other cultivars at all time points. At $2 \mathrm{~h}$ of stress, the expression of this gene in 'Arg' increased by about 4-times as compared to the control. But at 4 and $8 \mathrm{~h}$ of stress, expression decreased. In 'Roshan', early hours of stress were associated with the reduction in DHAR expression, but after 6 and 8 h, DHAR expression was about 2- and 5-times higher than in the control.

The maximum expression of the chlGR gene in 'Arg' was observed at $6 \mathrm{~h}$ of the stress, which was approximately 10-times higher than in the control. In 'Arta', the highest expression was obtained after $2 \mathrm{~h}$ of stress, and then a decreasing trend was observed. For 'Navid', a slight increase in gene expression was observed after 2 and $6 \mathrm{~h}$ of dehydration. In 'Roshan', the expression showed an upward trend with increasing stress duration except for $4 \mathrm{~h}$ of stress.

Relative water content of all the cultivars decreased gradually as the stress duration increased. However, tolerant 'Arg' and 'Roshan' had a significantly higher RWC than susceptible 'Arta' and 'Navid' at all time points (Fig. 3A).

Water loss rate of 'Arta' and 'Navid' was significantly higher than that of 'Arg' and 'Roshan' (Fig. 3B). Water loss rate of 'Arta' and 'Navid' gradually decreased as 


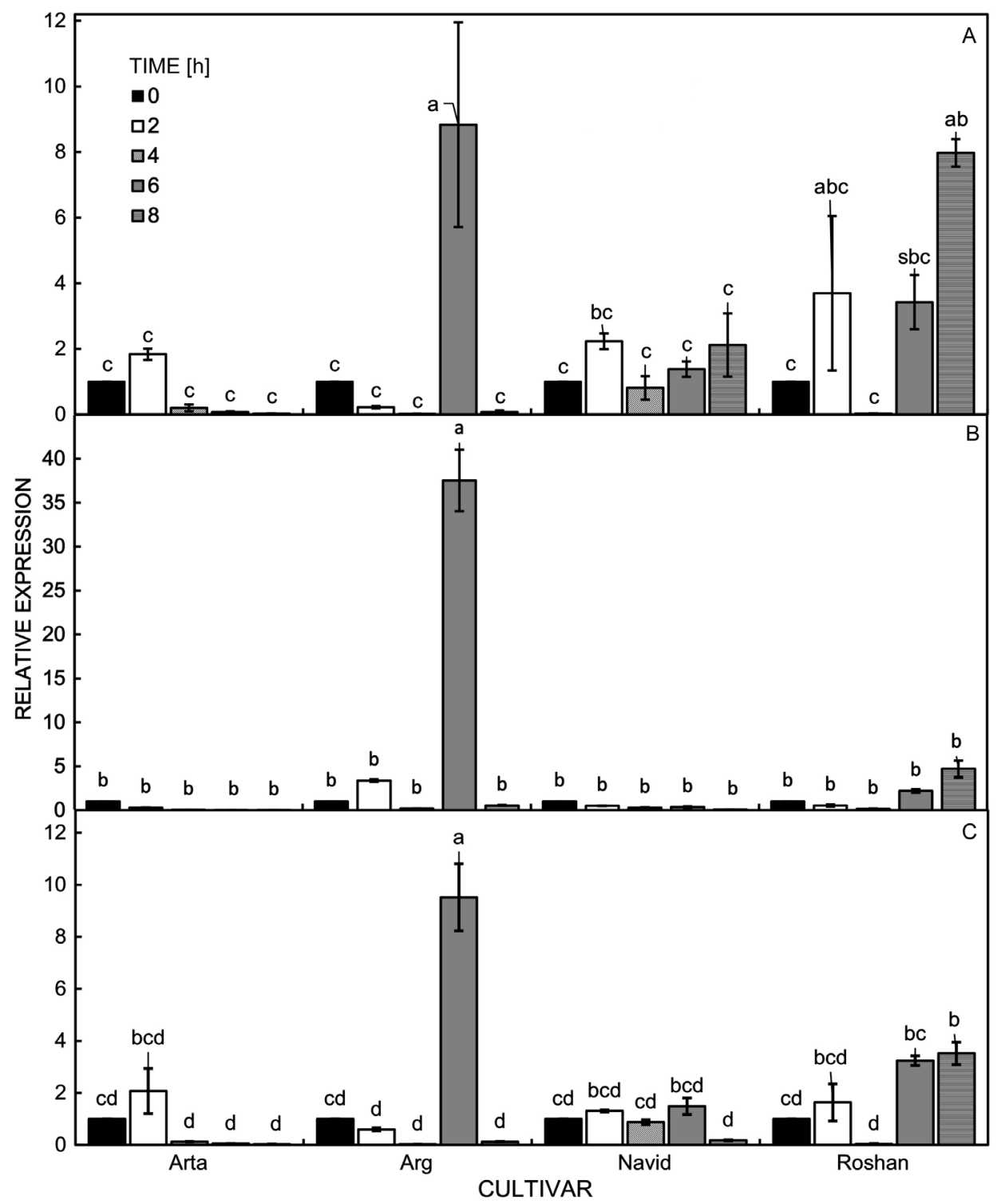

Fig. 2. Expression patterns of genes encoding enzymes of stromal section without the $S A P X$ gene in wheat cultivars 'Arta', 'Arg', 'Navid', and 'Roshan'. Means \pm SEs, $n=3$. Means with different letters are significantly different at $P \leq 0.05$ based on the Tukey test. Relative expressions of MDAR (A), DHAR (B), and chlGR (C).

stress duration increased. However, in 'Roshan', WLR at 2,4 , and $8 \mathrm{~h}$ of stress did not differ significantly.

Irregular activity of POX was observed in the studied cultivars at various time points (Fig. 4A). There was no significant difference between stress and non-stress treatments in 'Roshan', whereas in 'Arg', POX activity was significantly higher at $4 \mathrm{~h}$ of stress as compared to the control. Generally, a higher POX activity was observed under both stress and non-stress conditions in susceptible 'Arta' and 'Navid' as compared to tolerant 'Arg' and 'Roshan'.

Generally, susceptible 'Arta' and 'Navid' showed a higher content of MDA, especially at $6 \mathrm{~h}$ of stress, compared to tolerant 'Arg' and 'Roshan'. Content of MDA in 'Navid' increased at 2, 4, and $6 \mathrm{~h}$ of stress and then decreased at $8 \mathrm{~h}$. Although a slight increase in MDA content in 'Arg' was observed at 2, 4, and $6 \mathrm{~h}$ of stress, it was not significantly different from the control. In 'Roshan', MDA increased significantly at $2 \mathrm{~h}$ of stress in comparison to the control. Content of MDA decreased significantly at $8 \mathrm{~h}$ of stress as compared to 2,4 , and $6 \mathrm{~h}$ in both the tolerant cultivars (Fig. $4 B$ ).

Susceptible 'Arta' and 'Navid' showed a higher proline accumulation, especially after 6 and $8 \mathrm{~h}$ of dehydartion, than the tolerant cultivars. However, proline content for tolerant 'Roshan' at $4 \mathrm{~h}$ of stress was as high as that in the susceptible cultivars. Yet, during the next hours, its proline accumulation decreased so that the amount of proline at $8 \mathrm{~h}$ was not significantly different from the control. It should be mentioned that proline content of tolerant 'Arg' was also significantly lower than in the susceptible cultivars at non-stress conditions and remained almost constant 


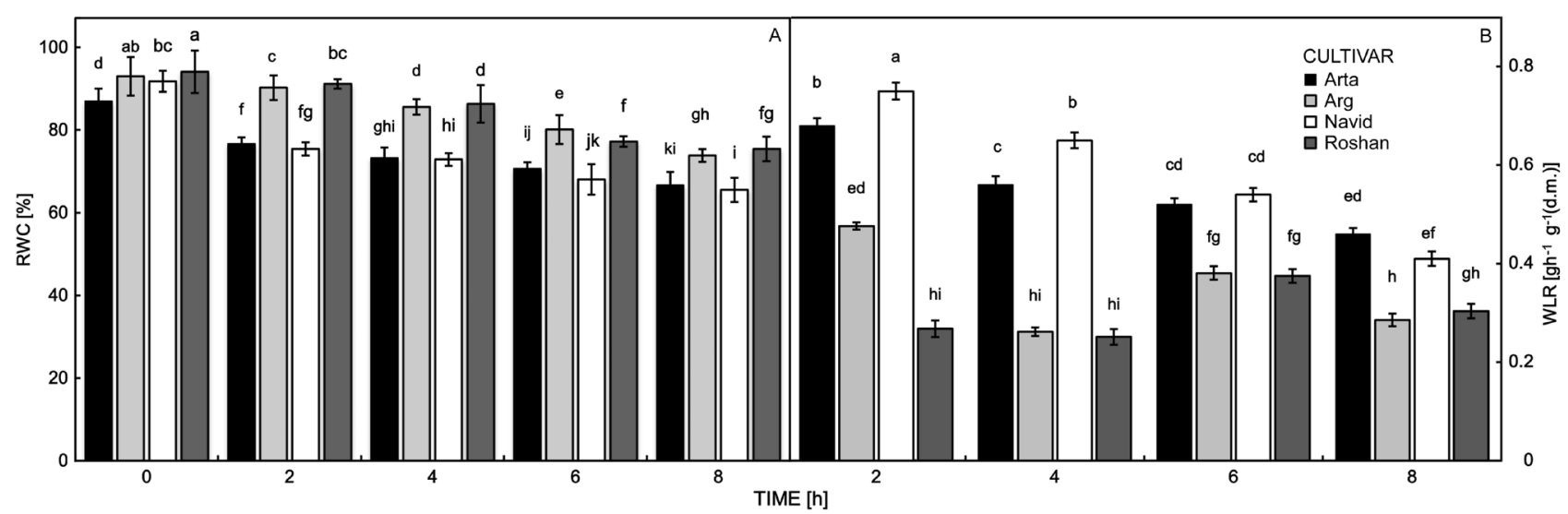

Fig. 3. Relative water content (RWC; $A$ ) and water loss rate (WLR, $B$ ) in wheat cultivars Arta, Arg, Navid, and Roshan under dehydration stress. Means \pm SEs, $n=3$. Means with different letters are significantly different at $P \leq 0.05$ based on the Tukey test.

during the whole stress, except at $6 \mathrm{~h}$, when it decreased significantly as compared to the control.

The results of principal component analysis shows that the first two principal components (PCA1 and PCA2) accounted for $69 \%$ of the total variation. Distributing the cultivars under the different time of dehydration based on the first and second components resulted in three groups (Fig. 1 Suppl.). Susceptible 'Arta' and 'Navid' (within the circle) were separated completely from tolerant 'Arg' and 'Roshan'. However, the tolerant genotypes were divided into two groups, mainly by the duration of dehydration stress; at a longer drought stress (6 and $8 \mathrm{~h}$ ), they were grouped together, except for 'Arg' at $8 \mathrm{~h}$ of stress.

The PCA1 is characterized mainly by lower expressions of $t A P X, c h l G R, M D A R, c h l C u / Z n S O D$, and DHAR. The PCA2 is determined mostly by a higher RWC and lower WLR and MDA. Thus, the susceptible cultivars had higher PCA1 and lower PCA2 scores (i.e., lower expressions of tAPX, chlGR, MDAR, chlCu/Zn SOD, and DHAR, and higher WLR and MDA content). On the other hand, the tolerant cultivars had mainly lower PCA1 scores (i.e., higher expressions of $t A P X, c h l G R, M D A R, c h l C u / Z n$ $S O D$, and $D H A R$, especially at a longer dehydration), and also higher PCA2 scores (a higher RWC and lower WLR and MDA), except for 'Arg' at $6 \mathrm{~h}$ of stress with the lowest amount of the PCA2 score.

\section{Discussion}

The increasing expression of genes encoding antioxidant enzymes acts as a protector of plant cells against oxidative stress caused by drought (Sečenji et al. 2010). The antioxidant enzymes associated with water-water and AsA-GSH cycles play an important role in stress tolerance (Hernández et al. 2009). Generally, the expression of the chlCu/Zn SOD gene in the tolerant cultivars was higher than in the susceptible cultivars under water stress (Xu et al. 2011). Increasing $\mathrm{Cu} / \mathrm{Zn}$ SOD expression in transgenic tobacco as compared to a wild-type improves the antioxidant defense system of chloroplast and increases tolerance to salinity, water, and osmotic stresses (Badawi et al. 2004). A higher expression of $C u / Z n S O D$ gene from Avicennia marina in the transgenic rice induces its better tolerance to drought stress than it is in a non-transgenic genotype (Parshanth et al. 2008). Furthermore, a higher expression of $\mathrm{Cu} / \mathrm{Zn} S O D$ and an increased activity of the respective enzyme results in an improved tolerance to salinity in rice seedlings (Kaminaka et al. 1998).

An increased expression of the MDAR gene was observed in the tolerant cultivars as compared to the susceptible ones. Various studies have reported the increase of MDAR expression under different stresses such as salinity, heat, drought, and cold in different plants (Ozturk et al. 2002, Chew et al. 2003, Yoon et al. 2004, Leterrier et al. 2005, Eltayeb et al. 2006, Sečenji et al. 2010). However, in Kentucky bluegrass, a decrease in $M D A R$ expression has been reported under drought stress by Xu et al. (2011). In our study, an increasing expression of this gene in the tolerant cultivars can be a reason for an increased MDAR activity resulting in a higher AsA content and a better tolerance to stress.

The susceptible cultivars showed a less DHAR gene expression as compared to the tolerant cultivars. This decrease in gene expression of the sensitive cultivars may be associated with a decreased activity of the related enzyme (Hosseini et al. 2015). The DHAR regenerates AsA from DHAsA (Asada 1999). As observed in this study, the decrease in expression of genes responsible for AsA regeneration (MDHAR and DHAR) in the sensitive cultivars caused a greater sensitivity to oxidative stress imposed by drought stress. Sečenji et al. (2010) observed an increased expression of chloroplast and cytosolic DHAR genes in tolerant cultivars of wheat under drought stress. Baek and Skinner (2003) reported that under cold stress, a tolerant wheat cultivar has a higher expression of these genes relative to a susceptible cultivar. In transgenic tobacco, an increased expression of DHAR results in an increased salinity tolerance (Eltayeb et al. 2006). In another study, DHAR expression in white clover increases under cold and cadmium stresses but remains constant under drought stress (Zhang et al. 2015).

In the present study, the tolerant cultivars generally showed a higher expression of the GR gene. Lascano et al. 


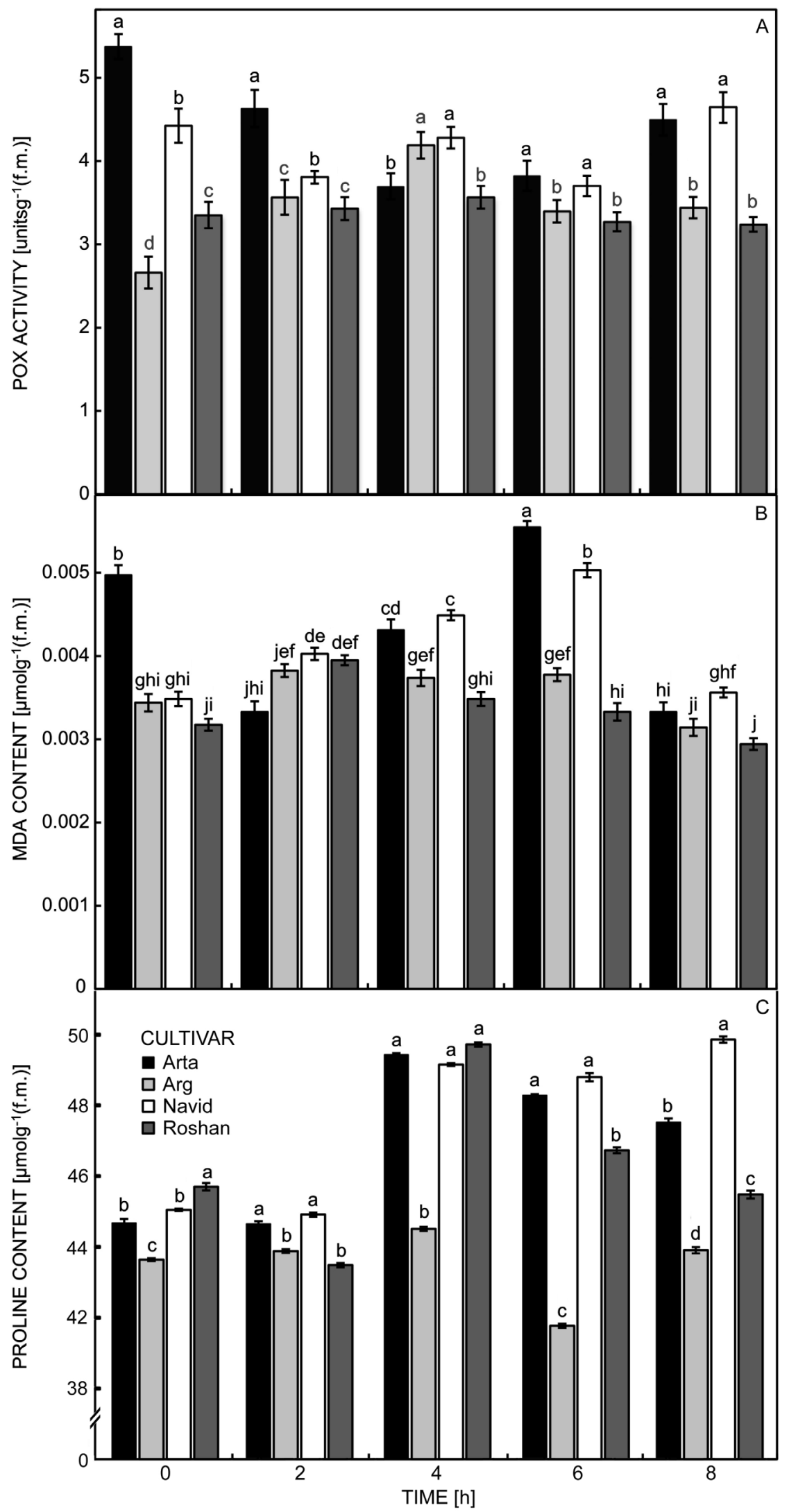

Fig. 4. Peroxidase (POX) activity $(A)$, malondialdehyde (MDA) accumulation $(B)$, and proline content $(C)$ in wheat cultivars Arta, Arg, Navid, and Roshan under dehydration stress. Means \pm SEs, $n=3$. Means with different letters are significantly different at $P \leq 0.05$ based on the Tukey test. 
(2003) reported that tolerant wheat genotypes has a higher content of GSH than non-tolerant genotypes. An increase in the expression of $G R$ in tolerant cultivars of wheat has also been reported by Sečenji et al. (2010).

The pattern of expressions of $c h l C u / Z n S O D$ and $t A P X$ genes was almost similar in the tolerant cultivars. Their expression increased in 'Arg' after 2 and $6 \mathrm{~h}$ and in 'Roshan' after 6 and $8 \mathrm{~h}$ of dehydration. However, in the sensitive cultivars, the expressions of both genes decreased with stress duration. An increase in the expression of the $c h l C u / Z n S O D$ gene in the tolerant cultivars was likely accompanied by an increased activity of the respective enzyme and as a result, by a greater amount of $\mathrm{O}_{2}{ }^{-}$converted to $\mathrm{H}_{2} \mathrm{O}_{2}$. Chloroplast uses APX to detoxify $\mathrm{H}_{2} \mathrm{O}_{2}$. As noted in this study, $A P X$ gene expression also increased and probably also the activity of APX, which neutralizes $\mathrm{H}_{2} \mathrm{O}_{2}$ to $\mathrm{H}_{2} \mathrm{O}$ and $\mathrm{O}_{2}$. An increased expression of $\mathrm{Cu} / \mathrm{Zn} \mathrm{SOD}$ and $A P X$ genes under drought stress has also been reported in chickpea (Mittler and Zilinskas 1994), Kentucky bluegrass (Xu et al. 2011), and white clover (Zhang et al. 2015).

Improvement in stress tolerance has been associated with an increase in the expression of genes encoding antioxidant enzymes (Baek and Skinner 2003, Xu et al. 2011). The AsA-GSH cycle is active in most cellular organelles, such as mitochondria, chloroplast, and cytoplasm, and consists of APX, MDAR, DHAR, and GR (Hernández et al. 2009). Two crucial non-enzymatic antioxidants are GSH and AsA and their redox state is provided from AsA-GSH cycle. Expressions of the genes encoding antioxidant enzymes related to AsAGSH cycle show that tolerant 'Arg' and 'Roshan' had higher expressions of them than susceptible 'Arta' and 'Navid', which increased the AsA and GSH redox state and improved tolerance of these cultivars to drought stress. These results are consistent with the findings of Baek and Skinner (2003), Sečenji et al. (2010) and Li et al. (2013) in wheat, Sultana et al. (2012) in rice, Ozturk et al. (2002) in barley, and Lee et al. (2007) and Eltayeb et al. (2007) in tobacco.

The tolerant cultivars had a higher RWC and a lower WLR than the non-tolerant genotypes, which is consistent with the finding of Rampino et al. (2006). The RWC is an appropriate indicator for screening drought tolerant cultivars and provides basic information about response to drought (Rampino et al. 2006, Wu et al. 2014). It has also a positive relationship with cell membrane stability (Mao et al. 2010).

The POX is not involved directly in water-water cycle, but it is one of the most important components of enzymatic defense that contributes to $\mathrm{H}_{2} \mathrm{O}_{2}$ detoxification. The POX activity in susceptible 'Arta' and 'Navid' was higher under both stress and non-stress conditions than in tolerant 'Arg' and 'Roshan'. These results are similar to the findings of Yang et al. (2011). In spite of the fact that peroxidases and catalases are present in most ROS-producing organelles, they are not very important for scavenging $\mathrm{H}_{2} \mathrm{O}_{2}$ caused by drought stress, and APX instead is very important for $\mathrm{H}_{2} \mathrm{O}_{2}$ sweeping (Hernández et al. 2012, Ara et al. 2013). As it was observed, the tolerant cultivars exhibited a higher expression of the $A P X$ gene, but the activity of POX in the tolerant cultivars was lower than in the susceptible genotypes.

The major product of membrane peroxidation is MDA. In our study, MDA content in the tolerant cultivars was lower than in the susceptible cultivars under higher drought stress. 'Arg' and 'Roshan' were more successful than 'Arta' and 'Navid' in protecting the integrity of membrane and had a lower MDA content. Similar results were reported in different plants under stress conditions (Sairam and Srivastana 2001, Bai et al. 2006, Moussa and Abdel-Aziz 2008).

Grouping cultivars based on principal component analysis mostly confirmed the results of evaluating the response of susceptible and tolerant cultivars to the dehydration stress for each of the studied attributes separately and the tolerant cultivars resisted better to drought stress as compared with the susceptible cultivars.

As concerns proline content, the response to drought stress was irregular in tolerant 'Arg' and 'Roshan'. A significant decrease was observed at some time points of drought stress and a significant increase at another time points. However, proline content increased in susceptible 'Arta' and 'Navid' after $4 \mathrm{~h}$ of dehydration. Increasing proline accumulation in the non-tolerant cultivars compared to the tolerant cultivars has also been reported by other researchers (Aziz et al. 1998, Ain-Lhout et al. 2001, Peuke et al. 2002, Vaidyananthan et al. 2003, Theerakulpisut et al. 2005, Rampino et al. 2006, Poustini et al. 2007, Nounjan et al. 2012, Tavakoli et al. 2016). A lower proline accumulation in the tolerant cultivars at higher stress as compared to the sensitive cultivars may be due to the higher expressions of genes encoding antioxidant enzymes, which lead to better ROS scavenging. Thus, the accumulation of $\mathrm{H}_{2} \mathrm{O}_{2}$ as a proline synthesis stimulator decreases (Yang et al. 2009). As shown in Fig. $4 C$, the maximum proline accumulation in 'Roshan' was after $4 \mathrm{~h}$ of dehydration when expressions of antioxidant enzyme encoding genes were lowest (Fig. 1 and 2). Water stress is inevitably associated with increasing oxidative stress due to an increased accumulation of ROS, especially $\mathrm{O}_{2}^{-}$and $\mathrm{H}_{2} \mathrm{O}_{2}$, in chloroplasts, mitochondria, and peroxisomes (Chakraborty and Pradhan 2012). Tolerant cultivars are better capable of scavenging ROS, including $\mathrm{H}_{2} \mathrm{O}_{2}$. A manifold increase in proline content along with a decreasing leaf potential and RWC is known issue (Rampino et al. 2006). Thus, another reason for the lower proline content in the tolerant cultivars can be attributed to the greater ability of these cultivars to maintain RWC due to less WLR.

Proline accumulation is one of the various plant strategies for improving osmotic adjustment and maintaining cellular functions. However, the reports on the importance of proline accumulation in conferring tolerance to drought stress are still contradictory and highly controversial (Hare and Cress 1997). Although proline content is generally higher in stress-tolerant than in stresssensitive plants, some reports have shown no positive relationship between proline accumulating potential and drought resistance (Hanson et al. 1977) and some others, similar to our results, have shown a larger proline content in 
sensitive cultivars than in tolerant cultivars under drought and salt stresses (Aziz et al. 1998, Ain-Lhout et al. 2001, Peuke et al. 2002, Vaidyananthan et al. 2003, Demiral and Türkan 2005, Theerakulpisut et al. 2005, Rampino et al. 2006, Poustini et al. 2007, Nounjan et al. 2012, Tavakoli et al. 2016). Therefore, it is not decided yet whether or not the increase in proline content can confer increased drought tolerance in plants (De Ronde et al. 2000, Nayyar and Walia 2003, Rampino et al. 2006).

\section{Conclusions}

The increase in the expression of genes encoding antioxidant enzymes in thylakoidal and stromal sections of chloroplasts in the tolerant cultivars improved their protection against oxidative damage caused by water stress as compared to the susceptible cultivars. Therefore, RWC was higher and WLR and MDA were lower in the tolerant cultivars than in the susceptible cultivars, possibly due to decreased cell membrane damage. However, proline accumulation was lower in the tolerant cultivars as compared to the susceptible ones due to better scavenging ROS including $\mathrm{H}_{2} \mathrm{O}_{2}$ (as a result of higher expressions of tAPX, chlGR, MDAR, chlCu/Zn SOD, and DHAR genes) and a greater ability to maintain RWC. Although POX activity of the tolerant cultivars was lower than in the susceptible cultivars, these cultivars used other antioxidant defense components.

\section{References}

Ain-Lhout, F., Zunzunegui, M., Barradas, M.D., Tirado, R., Clavijo, A., Novo, F.G.: Comparison of proline accumulation in two Mediterranean shrubs subjected to natural and experimental water deficit. - Plant Soil 230: 175-183, 2001.

Ara, N., Nakkanong, K., Lv, W., Yang, J., Hu, Z., Zhang, M.: Antioxidant enzymatic activities and gene expression associated with heat tolerance in the stems and roots of two cucurbit species ("Cucurbita maxima" and "Cucurbita moschata") and their interspecific inbred line "Maxchata". Int. J. mol. Sci. 14: 24008-24028, 2013.

Asada, K.: Production and scavenging of active oxygen in chloroplasts. - In: Scandalios, J.G. (ed.): Current Communications in Cell and Molecular Biology. 5. Molecular Biology of Free Radical Research Scavenging Systems. Pp. 173-192. Cold Spring Harbour Laboratory Press, New York 1992.

Asada, K.: The water-water cycle in chloroplasts: scavenging of active oxygens and dissipation of excess photons. - Annu. Rev. Plant Biol. 50: 601-639, 1999.

Aziz, A., Martin-Tanguy, J., Larher, F.: Stress-induced changes in polyamine and tyramine levels can regulate proline accumulation in tomato leaf discs treated with sodium chloride. - Physiol. Plant. 104: 195-202, 1998.

Badawi, G.H., Yamauchi, Y., Shimada, E., Sasaki, R., Kawano, N., Tanaka, K., Tanaka, K.: Enhanced tolerance to salt stress and water deficit by overexpressing superoxide dismutase in tobacco (Nicotiana tabacum) chloroplasts. - Plant Sci. 166: 919-928, 2004.

Baek, K.H., Skinner, D.Z.: Alteration of antioxidant enzyme gene expression during cold acclimation of near-isogenic wheat lines. - Plant Sci. 165: 1221-1227, 2003.

Bai, L.P., Sui, F.G., Ge, T.D., Sun, Z.H., Lu, Y.Y., Zhou, G.S.: Effect of soil drought stress on leaf water status, membrane permeability and enzymatic antioxidant system of maize. Pedosphere 16: 326-332, 2006.

Barrs, H.D., Weatherley, P.E.: A re-examination of the relative turgidity technique for estimating water deficits in leaves. Aust. J. biol. Sci. 15: 413-428, 1962.

Bates, L.S., Waldron, R.P., Teare, I.D.: Rapid determination of free proline for water stress studies. - Plant Soil 39: 205-217, 1973.

Chakraborty, U., Pradhan, B.: Oxidative stress in five wheat varieties (Triticum aestivum L.) exposed to water stress and study of their antioxidant enzyme defense system, water stress responsive metabolites and $\mathrm{H} 2 \mathrm{O} 2$ accumulation. - Braz. J. Plant Physiol. 24: 117-130, 2012.

Chance, B., Maehly, A.C.: Assay of catalases and peroxidases. Methods Enzymol. 2: 764-775, 1955.

Chaves, M.M., Maroco, J.P., Pereira, J.S.: Understanding plant responses to drought-from genes to the whole plant. - Funct. Plant Biol. 30: 239-264, 2003.

Chen, S., Zimei, L., Cui, J., Jiangang, D., Xia, X., Liu, D., Yu, J.: Alleviation of chilling-induced oxidative damage by salicylic acid pretreatment and related gene expression in eggplant seedlings. - Plant Growth Regul. 65: 101-108, 2011.

Chew, O., Whelan, J., Millar, A.H.: Molecular definition of the ascorbate-glutathione cycle in Arabidopsis mitochondria reveals dual targeting of antioxidant defenses in plants. - J. biol. Chem. 278: 46869-46877, 2003.

De Ronde, J.A., Spreeth, M.H., Cress, W.A.: Effect of antisense L- $\Delta$ 1-pyrroline-5-carboxylate reductase transgenic soybean plants subjected to osmotic and drought stress. - Plant Growth Regul. 32: 13-26, 2000.

Demiral, T., Türkan, İ.: Comparative lipid peroxidation, antioxidant defense systems and proline content in roots of two rice cultivars differing in salt tolerance. - Environ. exp. Bot. 53: 247-257, 2005.

Denby, K., Gehring, C.: Engineering drought and salinity tolerance in plants: lessons from genome-wide expression profiling in Arabidopsis. - Trends Biotechnol. 23: 547-552, 2005.

Eltayeb, A.E., Kawano, N., Badawi, G.H., Kaminaka, H., Sanekata, T., Morishima, I., Shibahara, T., Inanaga, S., Tanaka, K.: Enhanced tolerance to ozone and drought stresses in transgenic tobacco overexpressing dehydroascorbate reductase in cytosol. - Physiol. Plant. 127: 57-65, 2006.

Eltayeb, A.E., Kawano, N., Badawi, G.H., Kaminaka, H., Sanekata, T., Shibahara, T., Inanaga, S., Tanaka, K.: Overexpression of monodehydroascorbate reductase in transgenic tobacco confers enhanced tolerance to ozone, salt and polyethylene glycol stresses. - Planta 225: 1255-1264, 2007.

Flexas, J., Bota, J., Loreto, F., Cornic, G., Sharkey, T.D.: Diffusive and metabolic limitations to photosynthesis under drought and salinity in C3 plants. - Plant Biol. 6: 269-279, 2004.

Hanson, A.D., Nelsen, C.E. and Everson E.H.: Evaluation of free proline accumulation as an index of drought resistance using two contrasting barley cultivars. - Crop Sci. 17: 720726, 1977.

Harb, A., Awad, D., Samarah, N.: Gene expression and activity of antioxidant enzymes in barley (Hordeum vulgare L.) under controlled severe drought. - J. Plant Interact. 10: 109-116, 2015.

Hare, P.D., Cress, W.A.: Metabolic implications of stress-induced proline accumulation in plants. - Plant Growth Regul. 21: 79- 
$102,1997$.

Heath, R.L., Packer, L.: Photoperoxidation in isolated chloroplasts: I. Kinetics and stoichiometry of fatty acid peroxidation. - Arch. Biochem. Biophys. 125: 189-198, 1968.

Hernández, I., Alegre, L., Van Breusegem, F., Munné-Bosch, S.: How relevant are flavonoids as antioxidants in plants? Trends Plant Sci. 14: 125-132, 2009.

Hernández, I., Cela, J., Alegre, L., Munnébosch, S.: Antioxidant defenses against drought stress. In: Aroca, R. (ed.): Plant Responses to Drought Stress. Pp. 231-258. Springer, Berlin - Heidelberg 2012.

Hosseini, S.M., Hasanloo, T., Mohammadi, S.: Physiological characteristics, antioxidant enzyme activities, and gene expression in two spring canola (Brassica napus L.) cultivars under drought stress conditions. - Turk. J. Agr. Forest. 39: 413-420, 2015.

Kaminaka, H., Morita, S., Nakajima, M., Masumura, T., Tanaka, $\mathrm{K}$.: Gene cloning and expression of cytosolic glutathione reductase in rice (Oryza sativa L.). - Plant Cell Physiol. 39: 1269-1280, 1998.

Kang, H.M., Saltveit, M.E.: Chilling tolerance of maize, cucumber, and rice seedling leaves and roots are differentially affected by salicylic acid. - Physiol. Plant. 115: 571-576, 2002.

Lascano, H.R., Melchiorre, M.N., Luna, C.M., Trippi, V.S.: Effect of photooxidative stress induced by paraquat in two wheat cultivars with differential tolerance to water stress. Plant Sci. 164: 841-848, 2003.

Lee, Y.P., Kim, S.H., Bang, J.W., Lee, H.S., Kwak, S.S., Kwon, S.Y.: Enhanced tolerance to oxidative stress in transgenic tobacco plants expressing three antioxidant enzymes in chloroplasts. - Plant Cell Rep. 26: 591-598, 2007.

Leterrier, M., Corpas, F.J., Barroso, J.B., Sandalio, L.M., Luis, A.: Peroxisomal monodehydroascorbate reductase. Genomic clone characterization and functional analysis under environmental stress conditions. - Plant Physiol. 138: 21112123, 2005.

Li, G., Peng, X., Wei, L., Kang, G.: Salicylic acid increases the contents of glutathione and ascorbate and temporally regulates the related gene expression in salt-stressed wheat seedlings. Gene 529: 321-325, 2013.

Liu, X., Baird, W.M.: Differential expression of genes regulated in response to drought or salinity stress in sunflower. - Crop Sci. 43: 678-687, 2003.

Livak, K.J., Schmittgen, T.D.: Analysis of relative gene expression data using real-time quantitative PCR and the $2^{-\triangle \Delta C T}$ method. - Methods 25: 402-408, 2001.

Malatrasi, M., Close, T.J., Marmiroli, N.: Identification and mapping of a putative stress response regulator gene in barley. - Plant mol. Biol. 50: 141-150, 2002.

Mao, X., Zhang, H., Tian, S., Chang, X., Jing, R.: TaSnRK2.4, an SNF1-type serine/threonine protein kinase of wheat (Triticum aestivum L.), confers enhanced multistress tolerance in Arabidopsis. - J. exp. Bot. 61: 683-696, 2010.

McDonald, A.J.S., Davies, W.J.: Keeping in touch: responses of the whole plant to deficits in water and nitrogen supply. - Adv. bot. Res. 22: 229-300, 1996.

Mittler, R., Zilinskas, B.A.: Regulation of pea cytosolic ascorbate peroxidase and other antioxidant enzymes during the progression of drought stress and following recovery from drought. - Plant J. 5: 397-405, 1994.

Moussa, H.R., Abdel-Aziz, S.M.: Comparative response of drought tolerant and drought sensitive maize genotypes to water stress. - Aust. J. Crop Sci. 1: 31-36, 2008.

Nayyar, H., Walia, D.P.: Water stress induced proline accumulation in contrasting wheat genotypes as affected by calcium and abscisic acid. - Biol. Plant. 46: 275-279, 2003.
Nounjan, N., Nghia, P.T., Theerakulpisut, P.: Exogenous proline and trehalose promote recovery of rice seedlings from saltstress and differentially modulate antioxidant enzymes and expression of related genes. - J. Plant Physiol. 169: 596-604, 2012.

Ozturk, Z.N., Talamé, V., Deyholos, M., Michalowski, C.B., Galbraith, D.W., Gozukirmizi, N., Tuberosa, R., Bohnert, H.J.: Monitoring large-scale changes in transcript abundance in drought-and salt-stressed barley. - Plant mol. Biol. 48: 551573, 2002.

Peroni, L.A., Ferreira, R.R., Figueira, A., Machado, M.A., Stach-Machado, D.R.: Expression profile of oxidative and antioxidative stress enzymes based on ESTs approach of citrus. - Genet. mol. Biol. 30: 872-880, 2007.

Peuke, A.D., Schraml, C., Hartung, W., Rennenberg, H.: Identification of drought-sensitive beech ecotypes by physiological parameters. - New Phytol. 154: 373-387, 2002.

Poustini, K., Siosemardeh, A., Ranjbar, M.: Proline accumulation as a response to salt stress in 30 wheat (Triticum aestivum L.) cultivars differing in salt tolerance. - Genet. Resour. Crop Evol. 54: 925-934, 2007.

Prashanth, S.R., Sadhasivam, V., Parida, A.: Over expression of cytosolic copper/zinc superoxide dismutase from a mangrove plant Avicennia marina in Indica rice var. Pusa Basmati-1 confers abiotic stress tolerance. - Transgenic Res. 17: 281291, 2008.

Rampino, P., Pataleo, S., Gerardi, C., Mita, G., Perrotta, C.: Drought stress response in wheat: physiological and molecular analysis of resistant and sensitive genotypes. - Plant Cell Environ. 29: 2143-2152, 2006.

Ribas-Carbo, M., Taylor, N.L., Giles, L., Busquets, S., Finnegan, P.M., Day, D.A., Flexas, J.: Effects of water stress on respiration in soybean leaves. - Plant Physiol. 139: 466-473, 2005.

Rizhsky, L., Liang, H., Mittler, R.: The combined effect of drought stress and heat shock on gene expression in tobacco. - Plant Physiol. 130: 1143-1151, 2002.

Sairam, R.K., Srivastava, G.C.: Water stress tolerance of wheat (Triticum aestivum L.): variations in hydrogen peroxide accumulation and antioxidant activity in tolerant and susceptible genotypes. - J. Agron. Crop Sci. 186: 63-70, 2001.

Sečenji, M., Hideg, E., Bebes, A., Györgyey, J.: Transcriptional differences in gene families of the ascorbate-glutathione cycle in wheat during mild water deficit. - Plant Cell Rep. 29: $37-$ $50,2010$.

Simova-Stoilova, L., Demirevska, K., Petrova, T., Tsenov, N., Feller, U.: Antioxidative protection in wheat varieties under severe recoverable drought at seedling stage. - Plant Soil Environ. 54: 529-536, 2008.

Smirnoff, N.: The role of active oxygen in the response of plants to water deficit and desiccation. - New Phytol. 125: 27-58, 1993.

Sultana, S., Khew, C.Y., Morshed, M.M., Namasivayam, P., Napis, S., Ho, C.L.: Overexpression of monodehydroascorbate reductase from a mangrove plant (AeMDHAR) confers salt tolerance on rice. - J. Plant Physiol. 169: 311-318, 2012.

Suprunova, T., Krugman, T., Fahima, T., Chen, G., Shams, I., Korol, A., Nevo, E.: Differential expression of dehydrin genes in wild barley, Hordeum spontaneum, associated with resistance to water deficit. - Plant Cell Environ. 27: 12971308, 2004.

Tavakoli, M., Poustini, K., Alizadeh, H.: Proline accumulation and related genes in wheat leaves under salinity stress - J. agr. Sci. Technol. 18: 707-716, 2016.

Theerakulpisut, P., Bunnag, S., Kong-ngern, K.: Genetic 
diversity, salinity tolerance, and physiological responses to $\mathrm{NaCl}$ of six rice (Oryza sativa L.) cultivars. - Asian J. Plant Sci. 4: 562-573, 2005 .

Vaidyanathan, H., Sivakumar, P., Chakrabarty, R., Thomas, G.: Scavenging of reactive oxygen species in $\mathrm{NaCl}$-stressed rice (Oryza sativa L.) - differential response in salt-tolerant and sensitive varieties. - Plant Sci. 165: 1411-1418, 2003.

Wu, S., Hu, C., Tan, Q., Nie, Z., Sun, X.: Effects of molybdenum on water utilization, antioxidative defense system and osmoticadjustment ability in winter wheat (Triticum aestivum) under drought stress. - Plant Physiol. Biochem. 83: 365-374, 2014.

Xiaoqin, Y., Jianzhou, C., Guangyin, W.: Effects of drought stress and selenium supply on growth and physiological characteristics of wheat seedlings. - Acta Physiol. Plant. 31: 1031-1036, 2009.

$\mathrm{Xu}$, L., Han, L., Huang, B.: Antioxidant enzyme activities and gene expression patterns in leaves of Kentucky bluegrass in response to drought and post-drought recovery. - J. amer. Soc.
Hort. Sci. 136: 247-255, 2011.

Yang, S.L., Lan, S.S., Gong, M.: Hydrogen peroxide-induced proline and metabolic pathway of its accumulation in maize seedlings. - J. Plant Physiol. 166: 1694-1699, 2009.

Yang, Y., Zhang, Y., Wei, X., You, J., Wang, W., Lu, J., Shi, R.: Comparative antioxidative responses and proline metabolism in two wheat cultivars under short term lead stress. Ecotoxicol. environ. Safety 74: 733-740, 2011.

Yoon, H.S., Lee, H., Lee, I.A., Kim, K.Y., Jo, J.: Molecular cloning of the monodehydroascorbate reductase gene from Brassica campestris and analysis of its mRNA level in response to oxidative stress. - Biochim. Biophys. Acta Bioenerg. 1658: 181-186, 2004.

Zhang, Y., Li, Z., Peng, Y., Wang, X., Peng, D., Li, Y., He, X., Zhang, X., Ma, X., Huang, L., Yan, Y.: Clones of FeSOD, MDHAR, DHAR genes from white clover and gene expression analysis of ROS-scavenging enzymes during abiotic stress and hormone treatments. - Molecules 20: 20939-20954, 2015. 